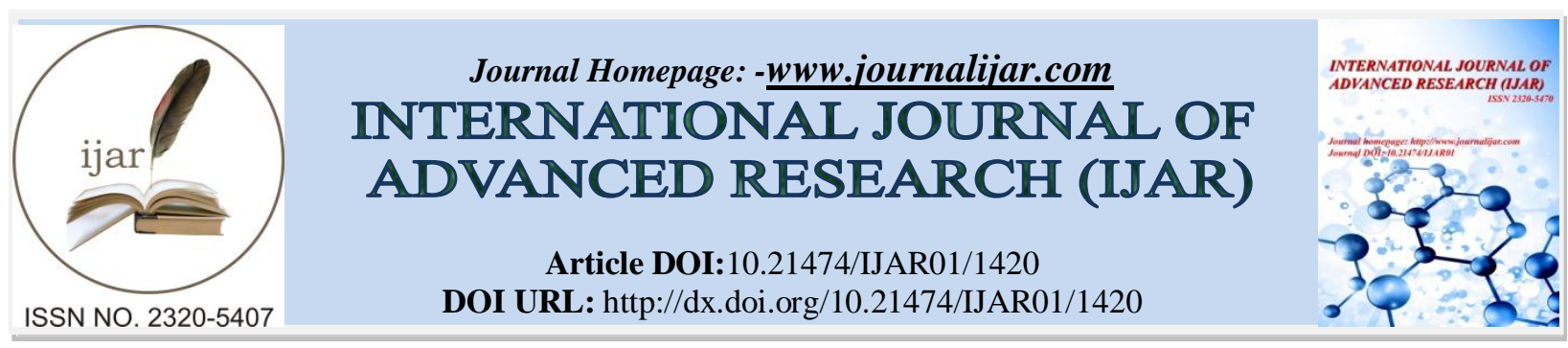

RESEARCH ARTICLE

\title{
DESIGN AND ANALYSIS OF CIRCULAR PATCH MICROSTRIP ARRAY ANTENNA IN ISM BAND FOR SPACE APPLICATIONS.
}

\section{G. Irene ${ }^{1}$ and Dr. Rajeshwari Mariappan ${ }^{2}$.}

1. Research Scholar, School of Electronics Engineering, VIT University, TN, India.

2. HOD, Electronics and Communication Engineering Dept., Kumaraguru College of Technology, TN, India.

\section{Manuscript Info}

Manuscript History

Received: 12 June 2016

Final Accepted: 13 July 2016

Published: August 2016

Key words:-

Circular patch, microstrip, array, antenna gain, radiation pattern, return loss.

\section{Abstract}

Microstrip antennas are highly popular because they have advantages due to their conformal and simple planar structure. This paper presents a circular patch microstrip array antenna operating in the S-band (2-4 $\mathrm{GHz})$, specifically in the ISM Band (2.40-2.45 GHz). The proposed circular patch array antenna will be light weight, flexible, slim and compact.

The proposed antenna is a $4 \times 4$ circular patch microstrip array antenna with equal size and equal spacing and was planed on a substrate with infinite ground. Inset fed microstrip line feed was used for feeding the antenna. The array antenna gives a return loss of $-18 \mathrm{db}$ and a gain of $17 \mathrm{dbi}$.

The network analyzer has been used to measure the return loss or the vswr measurement. A pattern measurement arrangement using the horn antenna as the antenna under test has been used to measure the radiation pattern. The measured results was in line with the simulated results.

\section{Introduction:-}

Microstrip patch antennas have become popular mainly because they have conformal and simple planar structure. Development of microstrip antennas was initiated in 1981, when a space-borne, light-weight, and low-profile planar array was needed for a satellite communication system. Since then, development of the microstrip antenna has been concentrated in three major programme areas: mobile satellite (MSAT) communication, earth remote sensing and deep-space exploration.

The proposed antenna works in the S-band and specifically in the ISM band. The main applications of the ISM band are in military, electronic news gathering and satellite broadcast, public provision of fixed wireless access, wireless networking like radio LANs, blue tooth and wifi. Short range RF identification devices, video applications, etc. also use ISM band. Proposed antenna has 16 elements and is arranged in a rectangular grid form and operated in TM11 mode. Each element has equal radius and an equal separation distance from their neighbours. The working principle of this antenna is that the conduction surface faces directly to the incoming signals. The voltage is equally distributed among all the elements. The voltage may superimpose and cancel each other due to the phase difference. Hence, the resultant voltage appears at the feed point. The microstrip feed induced voltages are fed into one point.

Corresponding Author:-G.Irene.

Address:-Research Scholar, School of Electronics Engineering, VIT University, TN,India. 
Circular microstrip antennas offer performance similar to that of rectangular geometries. In some applications such as arrays, circular geometries offer certain advantages over other configurations. Recent experimental results have shown that circular microstrip elements may be easily modified to produce a range of impedances, radiation patterns and frequencies of operation.

\section{The design of circular patch microstrip array antenna:-}

The design of circular patch microstrip array antenna begins with a single element. It is then developed into 16 elements and finally the total radiation pattern, gain and S-parameter are computed with the help of IE3D software.

\section{Circular patch antenna analysis:-}

The literature review has shown that the effective radius of circular patch can be found from the following equation[11].

where $r$ = radius of circular patch,

$$
r_{e f f}=r \sqrt{1+\frac{2 h}{\pi r \varepsilon_{r}}\left[\ln \left(\frac{\pi r}{2 h}\right)+1.7726\right]}
$$

$$
r=\frac{F}{\left\{1+\frac{2 h}{\pi \varepsilon_{r} F}\left[\ln \left(\frac{\pi F}{2 h}\right)+1.7726\right]\right\}^{1 / 2}}
$$

where

$$
F=\frac{8.791 \times 10^{9}}{f_{r} \sqrt{\epsilon_{r}}}
$$

$\varepsilon_{r}=$ dielectric constant of the substrate.

$f_{r}=$ resonant frequency

$h=$ height or thickness of the substrate,

$r=$ dielectric constant.

The effective area of the patch is then given by:

where $\mathrm{A}=$ area of the patch.

$$
A_{e f f}=\pi r_{e f f}^{2}
$$

\section{Resonant frequency of the circular patch:-}

The resonant frequencies of the circular patch can be analysed conveniently using the cavity model. The cavity is composed of two perfect electric conductors at the top and bottom to represent the patch and the ground plane, and a cylindrical perfect magnetic conductor around the circular periphery of the cavity.

Using the synthesis procedure, the resonant frequency of a circular patch can be computed from the following equation[4].

where $f_{0}=$ resonant frequency,

$$
f_{0}=\frac{c J_{m n}}{2 \pi r_{e f f} \sqrt{\varepsilon_{r}}}
$$

$J m n=m$ th zero of the derivative of the Bessel function of order $n$.

For dominant modeTM11, Jmn $=1.84118$ which is extensively used in all kinds of microstrip antennas.

Quality factor, bandwidth, directivity and efficiency of the circular patch:-

The quality factor, bandwidth and efficiency are figures of merit, and are interrelated, and there is no complete freedom to independently optimize each one. Therefore, there is always a tradeoff between them in arriving at an optimum antenna performance. However, there is a compulsion to optimize one of them while reducing the performance of the others.

The quality factor is a figure-of-merit that is representative of the antenna losses. For circular patch antenna, the total quality factor $Q t$ in general can be written as: 


$$
\frac{1}{Q_{t}}=\frac{1}{Q_{\text {rad }}}+\frac{1}{Q_{c}}+\frac{1}{Q_{d}}
$$

where $Q \mathrm{rad}=$ quality factor due to space wave losses,

$Q d=$ quality factor due to dielectric losses,

$Q c=$ quality factor due to ohmic losses.

The fractional bandwidth of the circular patch is inversely proportional to $Q t$. The VSWR at the input terminals is equal to or less than a desired maximum value over a band of frequencies, assuming that the VSWR is unity at the design frequency. Then taking into account of the impedance matching, we have

$$
\text { Bandwidth }=\frac{V S W R-1}{Q_{t} \sqrt{V S W R}}
$$

The above equation can be applied for rectangular patch antenna as well. The directivity of the circular patch is a measurement of the directional properties compared with those isotropic antennas. The tedium of numerical effort required to calculate the directivity of microstrip antenna has been addressed by many authors. The directivity of a circular microstrip antenna was computed by Derneryd. The computation of directivity is complicated as the expression involving integral contains the Bessel functions.

Recently, Mahony has simplified the computation by using the integral containing the Struve function. However, it requires tabulated data of Struve function and therefore, the expression is not convenient for fast calculations.

\section{An array of circular patches:-}

Sixteen circular patches can be arranged into an array in which each row and column of array consists of four elements. Figure 1. shows a $m x n$ array and the antenna facing the z-plane:

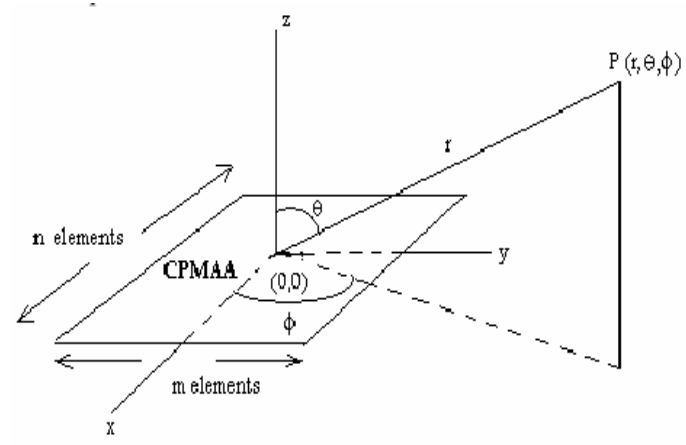

Figure 1:- $m x n$ array and the antenna facing the z-plane.

The array factor of the CPMAA is defined as[11]

$$
S_{\theta}\left(T_{x}, T_{y}\right)=\sum_{m=1}^{M-1} e^{j \frac{2 \pi m b}{\lambda}\left(T_{x}+\frac{\psi_{x}}{2 \pi b / \lambda}\right)} \times \sum_{n=1}^{N-1} e^{j \frac{2 \pi n d}{\lambda}\left(T_{y}+\frac{\psi_{y}}{2 \pi d / \lambda}\right)}
$$

where $b=$ spacing between elements in the $\mathrm{x}$ - direction,

$\mathrm{d}=$ spacing between elements in the $\mathrm{y}$-direction,

$T x=\sin \theta \cos \varphi$,

$T y=\sin \varphi \sin \theta$.

The total far field of the array is given by:

$E=E e(T x, T y) S(T x, T y)$

Basically the ability to receive the S-band signals depends on the array factor. The separation of each element is very important as this would affect the gain and radiation pattern of the circular patch microstrip array antenna. 


\section{Feed network design:-}

In the circular patch microstrip array antenna, each element is connected by a microstrip line which transforms the impedance of the patch into $50 \Omega$. If we have 16 elements, a complex network is formed.

This complex network is known as corporate-feed network, at which each element will be connected to the feed transmission lines. The corporate-feed network is used to provide power splits of $2 n$ (i.e. $n=2,4,8,16,32$, etc.) [11]This is accomplished by using either tapered lines to match the impedance of the elements to $50 \Omega$ coaxial or using quarter wavelength impedance transformer.

The $50 \Omega$ impedance matching is obtained in the array by using a quarter wave transformer.

where $Z_{\text {in }}$ is the input impedance,

$$
Z_{\text {out }}=\sqrt{Z_{\text {in }} \times Z_{L}}
$$

$\mathrm{Z}_{\mathrm{L}}$ is the load impedance, and

$\mathrm{Z}_{\text {out }}$ is the quarter wave transformed impedance.

This can be represented as shown in Figure 2. In this figure Zin is $50 \Omega$ and ZL is $100 \Omega$. The Zout obtained is 70.7 $\Omega$.

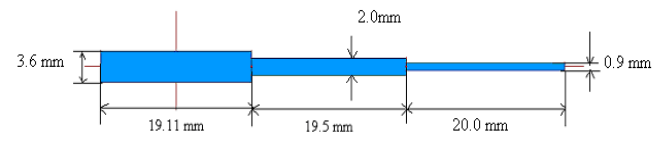

Figure 2:- Quarter wave transformation.

Corporate-feed networks are general and versatile. With this method, the model has more control on the feed of each element (amplitude and phase) and it is ideal for scanning phased arrays, multibeam arrays, or shaped-beam arrays.

The different authors who have designed and tested microstrip arrays indicate that radiation from the feed line, using corporate-feed network, is a serious problem that limits the cross-polarization and side lobe level of the arrays.

\section{Impedance of the circular patch microstrip array antenna:-}

To understand about the feed network design, one must understand the impedance.Looking at the current (magnetic field) and voltage (electrical field) for a single circular patch, the current is maximum at the centre and minimum near the left and right edges, while the electrical field is zero at the centre and maximum near the left and minimum near the right edges, as shown in Figure 3.

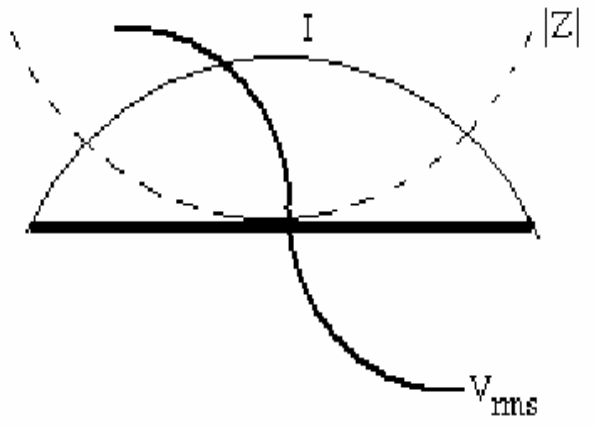

Figure 3:- Voltage, current and impedance measurement at resonance.

From the magnitude of the current and voltage, we can conclude that the impedance is minimum at the middle of the patch and maximum (around 200 which depends on the Q of the leaky cavity) near the edges. Hence, there is a point where the impedance is 50 along the "resonant length" at $\mathrm{x}$-axis of the element. 


\section{Microstrip line inset feeding:-}

The input impedance for a inset fed microstrip antenna is $50 \Omega$. Taking the reference as the centre of the coordinate system (i.e. $(\theta, \varphi)=(0,0))$ the input impedance at any radial distance $\theta^{1}=\theta_{0}$ from the center of the patch can be written as[11]

$$
R_{\text {in }}\left(\theta^{1}=\theta_{0}\right)=\frac{1}{G_{t}} \frac{J_{m}^{2}\left(k \theta_{0}\right)}{J_{m}^{2}\left(k a_{e}\right)}
$$

where $\mathrm{G}_{\mathrm{t}}=\mathrm{G}_{\mathrm{rad}}+\mathrm{G}_{\mathrm{c}}+\mathrm{G}_{\mathrm{d}}$,

$$
\begin{gathered}
G_{r a d}=\frac{\left(k_{0} a_{e}\right)^{2}}{480} \int_{0}^{\pi / 2}\left[J_{02}^{\prime 2}+\cos ^{2} \theta J_{02}^{2}\right] \sin \theta d \theta \\
G_{c}=\frac{\epsilon_{m o} \pi\left(\pi \mu_{0} f_{r}\right)^{-3 / 2}}{4 h^{2} \sqrt{\sigma}}\left[\left(k a_{e}\right)^{2}-m^{2}\right] \\
G_{d}=\frac{\epsilon_{m o} \tan \delta}{4 \mu_{0} h f_{r}}\left[\left(k a_{e}\right)^{2}-m^{2}\right]
\end{gathered}
$$

where fr represents the resonant frequency of the mn mode.

\section{Simulated Results:-}

The aim of this project is to develop an antenna with a directional pattern below -14 db and a gain of at least $12 \mathrm{dBi}$. And an antenna array for with equal spacing and uniform excitation was designed for space applications. The circular microstrip antenna was simulated by IE3D which is based on the method of moment.

The ground plane is infinite for this patch. By selecting proper values for microstrip line width and length and the position of the feed point, a good impedance bandwidth can be obtained. An inset feed scheme was employed to match the patch antenna to a $50 \Omega$ coaxial probe feed. The dielectric material has a permittivity of 3.38 and a thickness of $1.57 \mathrm{~mm}$. The material used is glass epoxy with 4003C.

The basic steps followed are: first the circular patch microstrip antenna array was developed by designing the single inset fed circular patch; then, a $1 \times 2$ array was developed; then, a $2 \times 2$ array was developed. The $2 \times 4$ array was then developed and finally the $4 x 4$ array was developed.

The inset fed circular patch microstrip antenna is shown in Figure 3.

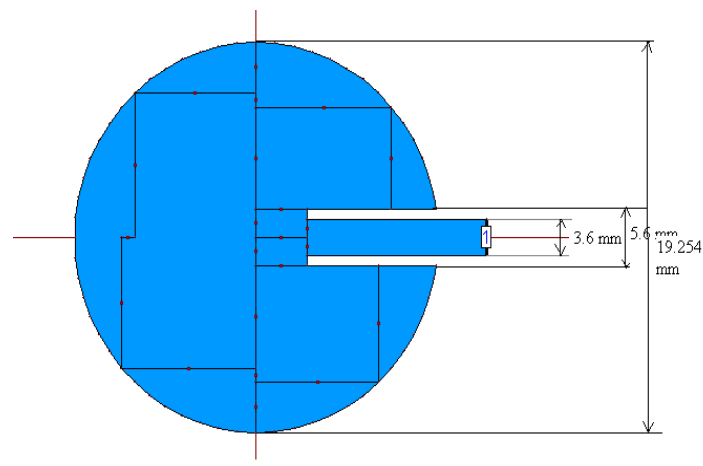

Figure 4:- A circular patch microstrip antenna.

Using design equations the radius of the antenna was found to be $19.254 \mathrm{~mm}$ for the given dielectric material and thickness.

The return loss of the single inset fed microstrip antenna, as simulated and shown in Figure. 4 is $-32.53 \mathrm{db}$ and it has a bandwidth of $25 \mathrm{MHz}$. 


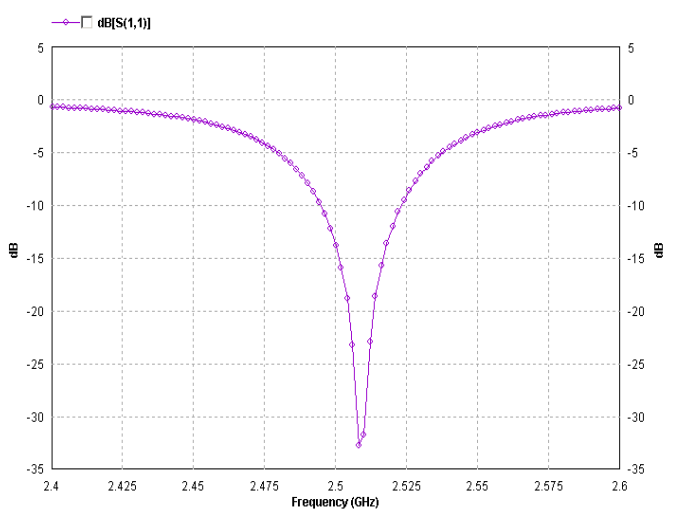

Figure 5:- Return loss or the reflection coefficient characteristics of the circular patch microstrip antenna.

The $4 x 4$ circular patch microstrip antenna array is shown in Figure 5.

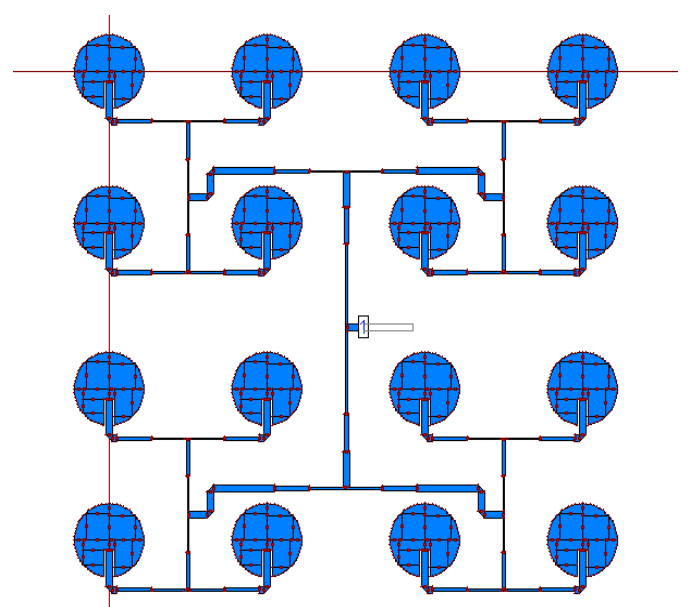

Figure 6:- A $4 x 4$ circular microstrip antenna array.

The radius of Microstrip patch antenna is $19.254 \mathrm{~mm}$ and inter element spacing between the two adjacent patches are $87.5 \mathrm{~mm}$ (i.e. $0.7 \lambda$ ) in both directions.

Figure 6 is the input reflection coefficient of the circular patch array antenna. It can be seen that the antenna array has a return loss of $-18.145 \mathrm{db}$ at a frequency of $2.516 \mathrm{GHz}$. The design frequency is $2.4 \mathrm{GHz}$. The bandwidth of the antenna is found to be $24 \mathrm{MHz}$.

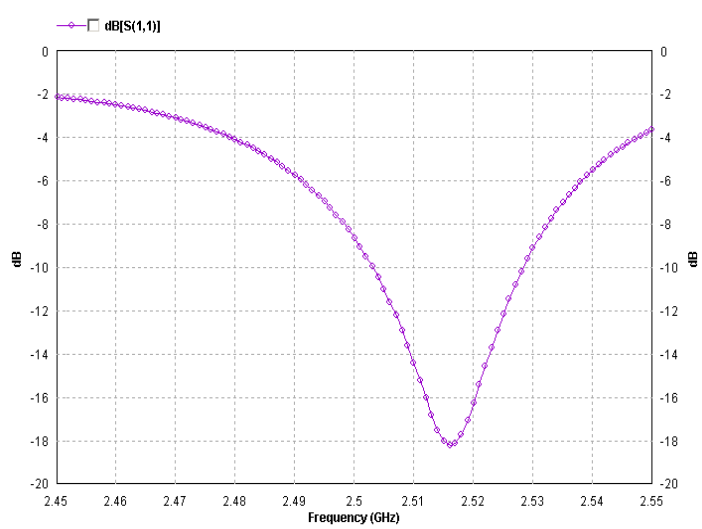


Figure 7:- Reflection coefficient vs frequency graph.

The elevation pattern gain display is shown in Figure 7. The gain of the antenna is $18.254 \mathrm{dbi}$.

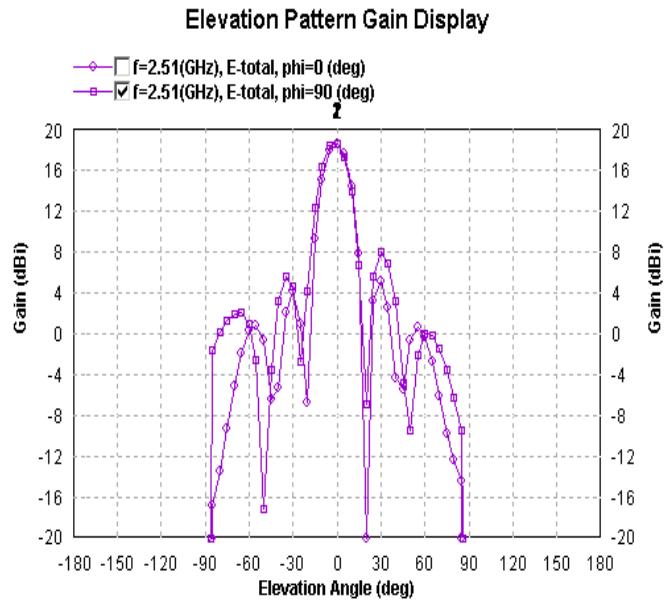

Figure 8:- The elevation pattern gain display graph.

The efficiency vs frequency graph is shown in Figure 8. The efficiency of the array antenna is more than $70 \%$.

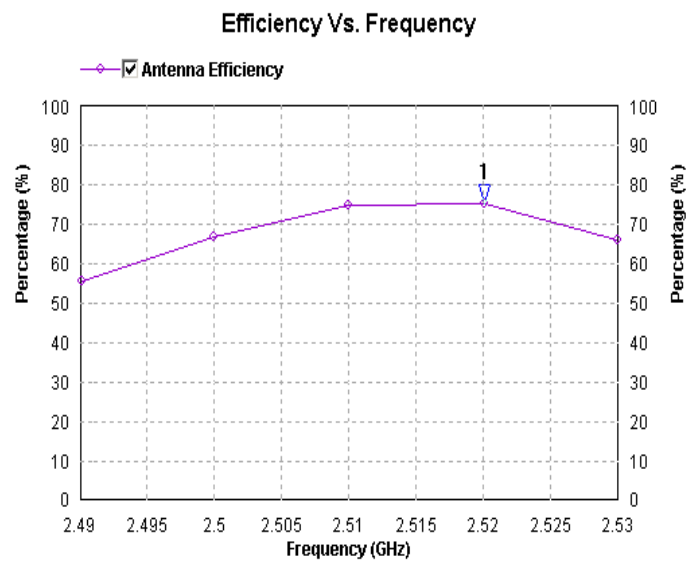

Figure 9:- Efficiency vs frequency graph.

\section{The S-band circular patch microstrip antenna array:-}

The photograph of the fabricated antenna is as shown in the Figure 9. The dielectric constant of the substrate is 3.38 and the height of the substrate is $1.57 \mathrm{~mm}$. 


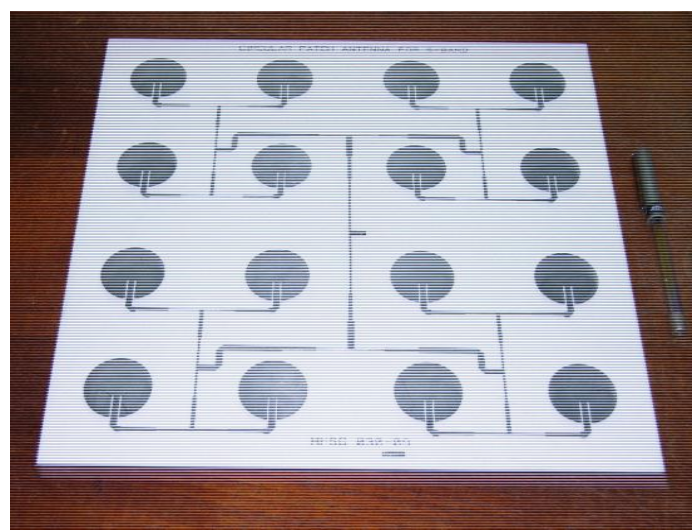

Figure 10:- S-band circular patch antenna array

\section{Measured Results:-}

\section{Return loss:-}

The vswr measurement using the network analyzer is as shown in Fig 10. The measured result was found to be $19.08 \mathrm{~dB}$ at $2.45 \mathrm{GHz}$. The change in frequency is due to the finite dielectric substrate used in the fabricated material.

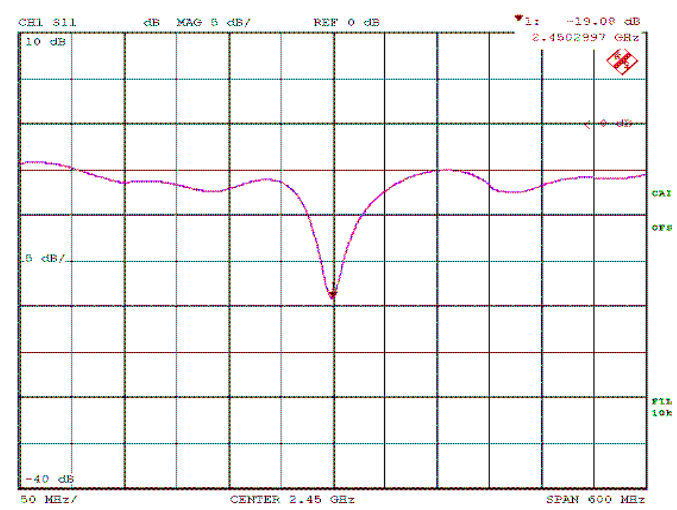

Figure 11:- The measured return loss curve.

The radiation pattern measurement:-

The radiation pattern has been measured using the radiation pattern measurement arrangement as show in figure 10, using the horn antenna as the antenna under test.

Here antenna under test (AUT) acts as receiving antenna situated under suitable illumination from transmitting antenna. The transmitting antenna is fixed in position and the AUT is rotated on a vertical axis by the antenna support shaft. Assuming that both antennas are linearly polarized, the $\mathrm{H}$-plane $\left[\mathrm{E}_{\varphi}\left(\theta=90^{\circ}, \varphi\right)\right]$ pattern is measured by rotating the antenna support shaft with both antennas horizontal. To measure E-plane $\left[E_{\varphi}(\theta, \varphi=0)\right]$ antenna support shaft is rotated with both antennas vertical

\section{Standard gain antenna used: horn antenna:-}

Frequency range: $1.7-2.6 \mathrm{GHz}$

Gain: $15.5 \mathrm{dBi}$

E - plane beamwidth: 30

$\mathrm{H}$ - plane beamwidth: 27 


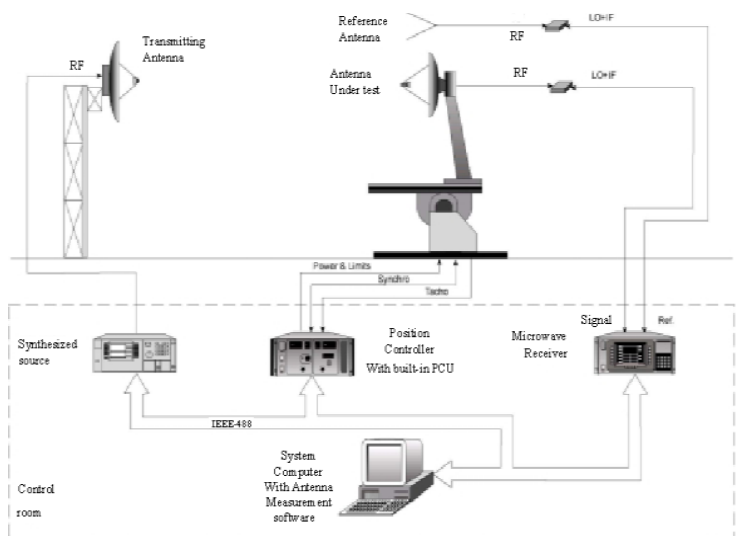

Figure 11:- Antenna measurement arrangement.

The radiation pattern measurement of the antenna in the E-plane is as shown in Figure 11.

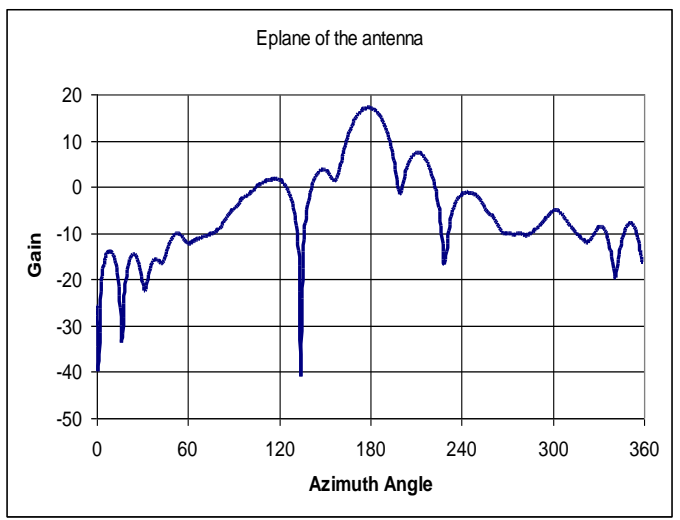

Figure 12:- E-plane of the antenna.

The radiation pattern of the E- plane was found to be $18 \mathrm{db}$. The radiation pattern measurement in the H-plane is as shown in Fig 12.

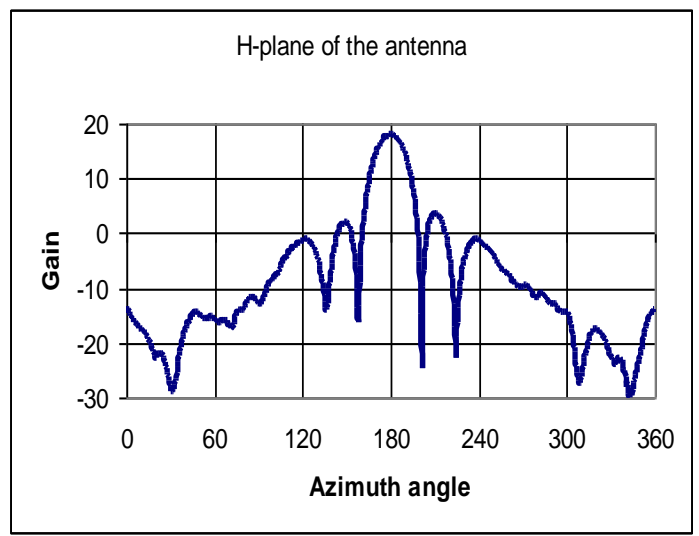

Figure 13:- H-plane of the antenna.

The radiation pattern of the H-plane was found to be $18.5 \mathrm{db}$. The measured values of both the E-plane and the Hplane was found to be nearly equal to that of the simulated values. 


\section{Conclusion:-}

All the results simulated are the optimum values generated by IE3D. From the simulation results, it is seen that the circular patch microstrip array antenna has high gain and very good return loss and it can be used for space applications. Changing the parameters like substance thickness, material, tangent loss and dielectric constant does affect the gain performance of the antenna.

The antenna has a very narrow bandwidth. The bandwidth of the array antenna is only around $1 \%$. The main disadvantage of the microstrip antenna is the narrow bandwidth. Many techniques like impedance matching, using multiple resonances and with reduced efficiency, can improve the bandwidth of the antenna. Further studies are therefore required.

\section{References:-}

1. Keshav Gupta, Kiran Jain, Pratibha Singh, "Analysis and design of circular microstrip patch antenna at 5.8GHz"., International Journal of Computer Science and Information Technologies, Vol 5(3), pp. 3895-3898, 2014.

2. Udith Raithatha, S.Sreenath Keshap, "Microstrip patch antenna for ISM applications". International Journal on Recent and Innovation trends in computing and Communication. Volume 2, Issue 7, July 2014.

3. Urvi Dhandha, Vivek.R, "Design and simulation of $4 * 1$ Probe feed rectangular patch array antenna for ISM Band applications", International Journal of Engineering Research and Technology, Volume 3, Issue 3, March 2014.

4. T.F.Lai, Wan Nor Liza Mahadi, Norhayati Soin, "Circular patch Microstrip array antenna for KU band"proceedings of world academy of science, engineering and technology volume36, pp. 2070-3740, December 2006.

5. Asghar Keshtkar, Ahmad Keshtkar and A.R.Dastkhosh, "Circular Microstrip patch array antenna for C-band altimeter system"-International journal of antennas and propagation, Volume 2008 Article ID 389418.

6. M.Ramesh and Yip K.B, "Design formula for inset fed Microstrip patch antenna". Journal of microwaves and optoelectronics, Vol 3 No.,3 December 2003.

7. E. O. Hammerstad, "Equations for Microstrip Circuit Design," Proc. Fifth European Microwave Conf, pp. 26827, September 1975.

8. Ahmed El Oualkadi, "Design of Rectangular Ring Patch Antenna forISM Band at $2.45 \mathrm{GHz}$, Recent Advances in Circuits, Systems, Telecommunications and Control ISBN: 978-960-474-341-4.

9. Chakkrit Kamtongdee and Nantakan Wongkasem, "A Novel Design of Compact $2.4 \mathrm{GHz}$ Microstrip Antennas",978-1-4244-3389/09/\$25.00 @2009 IEEE.

10. Indrasen Singh and Dr. V.S. Tripathi, "Micro strip Patch Antenna and its Applications: a Survey", Int. J. Comp. Tech. Appl., Vol 2 (5),1595- 1599.

11. Sunil Singh, Neelesh Agarwal, Navendu Nitin and Prof.A.K.Jaiswal,"Design consideration of Microstrip Patch Antenna", InternationalJournal of Electronics and Computer Science Engineering ISSN-2277- 1956.

12. Balanis C. A, "Microstrip Antennas", Antenna Theory, Analysis and Design, Third Edition, John Wiley \& Sons, pp-811-876, 2010.

13. Ramesh Garg, Prakash Bhartia , Inder Bahl, Apisak Ittipiboon, "Microstrip Antenna Design Handbook", Artech House Inc. Norwood, MA, pp. 1-68, 253-316, 2001.

14. David M.Pozar," Microwave Engineering", Fourth Edition, JohnWZhi. Ning.Chen and Michael. Y.W.Chia, Broadband planar antennas - design and applications, John Wiley and Sons, Ltd. 